OPEN ACCESS

Edited by:

Gustavo Santoyo,

Universidad Michoacana de San

Nicolás de Hidalgo, Mexico

Reviewed by:

Rungroch Sungthong,

Chulalongkorn University, Thailand

Haiyan Li,

Kunming University of Science and

Technology, China

Shenzheng Zeng,

Sun Yat-sen University, China

*Correspondence:

Zhiwei Yang

yangzw@cnu.edu.cn

Weiping Wang

wangweiping@hhrrc.ac.cn

tThese authors have contributed equally to this work

Specialty section: This article was submitted to Microbial Symbioses, a section of the journal

Frontiers in Microbiology

Received: 10 August 2021

Accepted: 04 October 2021

Published: 16 November 2021

Citation:

Chu C, Fan M, Song C, Li N,

Zhang C, Fu S, Wang W and Yang Z (2021) Unveiling Endophytic Bacterial Community Structures of Different Rice Cultivars Grown in a

Cadmium-Contaminated Paddy

Field

Front. Microbiol. 12:756327. doi: 10.3389/fmicb.2021.756327

\section{Unveiling Endophytic Bacterial Community Structures of Different Rice Cultivars Grown in a Cadmium- Contaminated Paddy Field}

\author{
Chaoqun $\mathrm{Chu}^{1+}$, Meiyu Fan ${ }^{1+}$, Chongyang Song ${ }^{1}, \mathrm{Ni} \mathrm{Li}^{2}$, Chao Zhang ${ }^{2}$, Shaowei $\mathrm{Fu}^{1}$, \\ Weiping Wang ${ }^{2 *}$ and Zhiwei Yang ${ }^{1 *}$
}

${ }^{1}$ College of Life Sciences, Capital Normal University, Beijing, China, ${ }^{2}$ State Key Laboratory of Hybrid Rice, Hunan Hybrid Rice Research Center, Changsha, China

Endophytic bacteria play potentially important roles in the processes of plant adaptation to the environment. Understanding the composition and dynamics of endophytic bacterial communities under heavy metal (HM) stress can reveal their impacts on host development and stress tolerance. In this study, we investigated root endophytic bacterial communities of different rice cultivars grown in a cadmium (Cd)-contaminated paddy field. These rice cultivars are classified into low (RBQ, 728B, and NX1B) and high (BB and S95B) levels of Cd-accumulating capacity. Our metagenomic analysis targeting 16S rRNA gene sequence data reveals that Proteobacteria, Firmicutes, Actinobacteria, Acidobacteria, Bacteroidetes, and Spirochaetes are predominant root endophytic bacterial phyla of the five rice cultivars that we studied. Principal coordinate analysis shows that the developmental stage of rice governs a larger source of variation in the bacterial communities compared to that of any specific rice cultivar or of the root $\mathrm{Cd}$ content. Endophytic bacterial communities during the reproductive stage of rice form a more highly interconnected network and exhibit higher operational taxonomic unit numbers, diversities, and abundance than those during the vegetative stage. Forty-five genera are significantly correlated with Cd content in rice root, notably including positive-correlating Geobacter and Haliangium; and negative-correlating Pseudomonas and Streptacidiphilus. Furthermore, Phylogenetic Investigation of Communities by Reconstruction of Unobserved States analysis shows that functional pathways, such as biosynthesis of siderophore and type II polyketide products, are significantly enhanced during the reproductive stage compared to those during the vegetative stage under $\mathrm{Cd}$ stress. The isolated endophytic bacteria from the Cd-contaminated rice roots display high Cd resistance and multiple traits that may promote plant growth, suggesting their potential application in alleviating HM stress on plants. This study describes in detail for the first time the assemblage of the bacterial endophytomes of rice roots under $\mathrm{Cd}$ stress and may provide insights into the interactions among endophytes, plants, and HM contamination.

Keywords: rice, endophytic bacteria, community structure, co-occurrence network, developmental stage, cadmium contamination, plant growth-promoting bacteria 


\section{INTRODUCTION}

Pollution of soil with heavy metal (HM) is widespread due to the rapid development of industry and extensive application of chemical fertilizers and pesticides (Huang and Jin, 2008; Atafar et al., 2010). HMs have harmful effects on crops and soil microorganisms and weaken the function of soil ecosystems (Kossoff et al., 2014; Guo et al., 2020). Therefore, remediation of HM-contaminated soil is a challenging task which holds great promise to improve the soil environment and to ensure safer food production.

Traditional methods for remediation of HM-contaminated soil rely heavily on physical and chemical approaches that are costly and non-sustainable. In recent years, biological remediation methods which take advantage of the metal-microbe interaction that occurs in plant hosts have been exploited (Etesami, 2018; Yin et al., 2019). Compared to bulk soil microbiomes, plantassociated microbiomes, such as endophytic and rhizospheric bacteria, have shown promise for HM remediation (Afzal et al., 2019). Endophytes are microorganisms living in the plant interior without causing disease. Beneficial endophytes not only promote plant growth but also help to remediate environmental contaminants (Etesami, 2018). Under metal stress, endophytic bacteria assist in phytoextraction and phytoremediation by increasing the biomass of HM-hyperaccumulating plants and enhancing the metal uptake by plants via acidifying the rhizosphere environment, thus enhancing the availability of metals (Rajkumar et al., 2012; Ma et al., 2016; Luo et al., 2019). In recent times, some HM-tolerant endophytes have been shown to promote plant growth in HM-contaminated soils and reduce the uptake of toxic metals by plants via biosorption, precipitation, complexation, and enzymatic transformation - ultimately leading to safer methods for human food production (Etesami, 2018; Yin et al., 2019).

Under HM stress, plants are capable of recruiting specific endophytic populations that enable a high HM resistance and plant growth-promoting properties (Croes et al., 2013; Pereira and Castro, 2014; Montalban et al., 2016; Syranidou et al., 2018; Sun et al., 2019; Zadel et al., 2020). Furthermore, these microbes have been shown to influence HM uptake by plants (Luo et al., 2017, 2019). For example, in the well-known cadmium $(\mathrm{Cd}) /$ zinc $(\mathrm{Zn})$ superaccumulator Sedum alfredii, the enrichment of Bacteroidetes and depletion of Firmicutes and Planctomycetes in the endosphere of HP (hyperaccumulating) genotype may be responsible for the metal hyper-content in its shoots (Luo et al., 2017). Subsequent studies have shown that the abundance of Streptomycetaceae, Nocardioidaceae, and Pseudonocardiaceae is strongly correlated with an increased shoot biomass and total $\mathrm{Cd} / \mathrm{Zn}$ accumulation in $S$. alfredii (Luo et al., 2019). An inoculation of $S$. alfredii with a synthetic bacterial community resulted in a significant improvement in plant biomass, root morphology, and $\mathrm{Cd} / \mathrm{Zn}$ accumulation (Luo et al., 2019).

Compared to other crops, rice can easily incorporate more $\mathrm{Cd}$ and is the major source of dietary Cd intake in populations that rely principally on rice ( $\mathrm{Hu}$ et al., 2016; Wang et al., 2019). Several studies have shown that bacteria inhabiting the rhizoplane and rhizosphere of rice can have a great influence on rice growth and uptake of HMs (Hu et al., 2015, 2019; Hou et al., 2018). However, few studies analyzing the endophytic bacteria under HM conditions in rice have been carried out. Zhou et al. (2020) showed that inoculation of rice endophytic Stenotrophomonas sp. R5-5 can change the relative abundance of some Cd-resistant bacteria in rice plants and downregulate the expression of rice $\mathrm{Cd}$ transporters, thereby reducing the accumulation of $\mathrm{Cd}$ in rice. An arsenic (As)-resistant facultative endophytic bacterium, Serratia sp. F2, can lower As accumulation in rice grain via increasing As adsorption by $\mathrm{Fe}$ plaque on the root surface (Cheng et al., 2020). These studies demonstrate that specific HM-tolerant microbes can significantly influence $\mathrm{HM}$ accumulation in rice. However, little is known about the composition and function of the microbiomes that colonize the endosphere of rice roots under HM stress. To better understand the ecological roles of endophytes with their host plants, it is crucial to investigate and characterize endophytic populations in rice grown in a HM-contaminated environment.

Here, we present a detailed investigation of the root bacterial endophytomes of rice grown in a Cd-contaminated paddy field using low- and high-Cd-accumulating cultivars. We employed bacterial $16 \mathrm{~S}$ ribosomal RNA gene amplicon sequencing to (1) analyze the composition and dynamic changes of endophytic bacteria communities at two developmental stages of rice (2) decipher the keystone taxa that define the bacterial population structure (3) identify bacterial biomarkers that are uniquely associated with each individual rice cultivar, and (4) analyze the endophytic bacterial taxa correlated with $\mathrm{Cd}$ content. In addition, we identified metabolic pathways and functional genes enriched in root endophytic communities under Cd stress. Finally, we isolated and characterized bacterial endophytes from the Cd-contaminated rice roots as potential bio-inoculants to enhance crop productivity and mitigate HM stress.

\section{MATERIALS AND METHODS}

\section{Rice Seeds}

Rice (Oryza sativa L.) seeds were provided by the Hunan Hybrid Rice Research Center (HHRRC), China. RBQ (Nipponbare), as a model plant, is a japonica cultivar. $728 \mathrm{~B}$, $\mathrm{NX1B}, \mathrm{BB}$, and S95B are indica cultivars bred by HHRRC. After years of cultivation, we observed that when soil-available $\mathrm{Cd}$ is $0.45-2.3 \mathrm{mg} / \mathrm{kg}, \mathrm{RBQ}, 728 \mathrm{~B}$, and NX1B accumulate $0.08-0.48 \mathrm{mg} \mathrm{Cd} / \mathrm{kg}$ grains, while $\mathrm{BB}$ and $\mathrm{S} 95 \mathrm{~B}$ accumulate $0.37-0.91 \mathrm{mg} \mathrm{Cd} / \mathrm{kg}$ grains. Because these two groups of cultivars accumulate significantly different amounts of $\mathrm{Cd}$ in grains, we classify RBQ, 728B, and NX1B as low-accumulating (LA) cultivars and $\mathrm{BB}$ and $\mathrm{S} 95 \mathrm{~B}$ as high-accumulating (HA) cultivars. The entire development phase for all five cultivars is 100 to 112 days.

\section{Rice Cultivation and Sampling}

From June to October 2018, five rice cultivars (RBQ, 728B, $\mathrm{NX} 1 \mathrm{~B}, \mathrm{BB}$, and $\mathrm{S} 95 \mathrm{~B}$ ) were cultivated in a Cd-contaminated 
paddy field $\left(27^{\circ} 58 \mathrm{~N}, 113^{\circ} 28^{\prime} \mathrm{E}\right)$ in Liling, Hunan province, China. This region is characterized by a humid subtropical monsoon climate with the following annual means: temperature, $18^{\circ} \mathrm{C}$; sunshine, $1,500-1,910 \mathrm{~h}$; rainfall, 1,300-1,600 mm; and frost-free period, 288 days. The paddy field is contaminated by $\mathrm{Cd}$ due to a historic $\mathrm{Zn}-\mathrm{Pb}$ ore mine in Liling. The soil of the experimental area has the following characteristics: $\mathrm{pH}$ 5.4; electrical conductivity, $198.7 \mu \mathrm{s} / \mathrm{cm}$; water content, $51.2 \%$; organic content, $3.2 \%$; organic carbon content, $13.7 \mathrm{~g} / \mathrm{kg}$; total nitrogen content, $2.8 \mathrm{~g} / \mathrm{kg}$; available phosphorus, $14.2 \mathrm{mg} / \mathrm{kg}$; available potassium, $181.9 \mathrm{mg} / \mathrm{kg} ; \mathrm{NH}_{4}{ }^{+}-\mathrm{N}, 220.6 \mathrm{mg} / \mathrm{kg}$; and $\mathrm{NO}_{3}{ }^{-}-\mathrm{N}, 0.4 \mathrm{mg} / \mathrm{kg}$. Cd, chromium, manganese, copper, and lead are $0.9,69.0,53.4,28.8$, and $52.1 \mathrm{mg} / \mathrm{kg}$, respectively. Among them, Cd content is $0.9 \mathrm{mg} / \mathrm{kg}$, which greatly exceeds the risk screening value $(0.3 \mathrm{mg} / \mathrm{kg})$ defined by China Risk for soil contamination on agricultural land (Trial; GB15618-2018).

The field experiment employed a randomized block design with five rice cultivars. Before use, the plot was fully ploughed and divided into 15 zones $(200 \times 60 \mathrm{~cm})$ with an interval of $40 \mathrm{~cm}$ between each zone. There were three columns in one zone, 10 holes in one column, and two seedlings in each hole. There were three replicates (zones) for each cultivar. Non-polluted water was used for irrigation. Water and fertilizer management was carried out according to the local customs.

Thirty days (vegetative stage) and 60 days (reproductive stage) after transplantation, rice root samples were collected. For each cultivar, five individuals were sampled according to diagonal sampling method in each zone, and the roots were mixed. The root samples were transported back to the laboratory under low temperature. Root samples were divided into two parts: one part was washed and air-dried, frozen in liquid nitrogen, and stored at $-80^{\circ} \mathrm{C}$ for later DNA extraction and $16 \mathrm{~S}$ rDNA amplification, while another part was stored at $4^{\circ} \mathrm{C}$ until isolation of endophytic bacteria. Root samples for the five rice cultivars at the vegetative stage were referred to as RBQ1, 728B1, NX1B1, $\mathrm{BB} 1$, and $\mathrm{S} 95 \mathrm{~B} 1$ and at the reproductive stage as RBQ2, 728B2, NX1B2, BB2, and S95B2.

\section{Determination of Cd Content in Roots}

Roots were washed, deactivated at $105^{\circ} \mathrm{C}$ for $30 \mathrm{~min}$, and dried at $55^{\circ} \mathrm{C}$ for $48 \mathrm{~h}$ and then $0.5 \mathrm{~g}$ roots were pulverized in an agate mortar. The $\mathrm{Cd}$ content of root samples was determined using inductively coupled plasma mass spectrometry (ICP-MS) by Advanced Standards Technical Services Co., Ltd (Beijing). There were three replicates for each sample.

\section{DNA Extraction, PCR Amplification of 16S rDNA, and Sequencing}

$0.5 \mathrm{~g}$ sample of rice roots from each cultivar was washed and surface-sterilized in triplicate, as described previously (MorontaBarrios et al., 2018). There were three replicates for each cultivar. The effect of sterilization was verified by plating the last wash solution $(100 \mu \mathrm{l})$ on LB plates before proceeding with DNA extraction.

Endophytic bacterial DNA was extracted using the FastDNA ${ }^{\circledR}$ Spin Kit for Soil (MP-Bio) according to the manufacturer's protocols. DNA quantity and purity were measured using NanoDrop 2000 (Thermo Scientific, Wilmington, DE, United States). As described previously (Bulgarelli et al., 2015), the V5-V7 hypervariable regions of the bacterial 16S rRNA genes were amplified with primers $799 \mathrm{~F}$ (5'-AACMGGATTAGATACCCKG-3') and 1193R (5'-ACGTCATCCCCACCTTCC-3') via thermocycler PCR system (GeneAmp 9700, ABI, United States). PCR reactions were conducted using the following settings: $3 \mathrm{~min}$ initiation at $95^{\circ} \mathrm{C}, 27 \mathrm{cycles}$ of $30 \mathrm{~s}$ denaturation at $95^{\circ} \mathrm{C}, 30 \mathrm{~s}$ annealing at $55^{\circ} \mathrm{C}$, and $45 \mathrm{~s}$ elongation at $72^{\circ} \mathrm{C}$, and a final extension at $72^{\circ} \mathrm{C}$ for $10 \mathrm{~min}$. PCR reactions were performed in triplicate with a $20 \mu \mathrm{l}$ mixture containing $4 \mu \mathrm{l}$ of $5 \times$ FastPfu Buffer, $2 \mu \mathrm{l}$ of $2.5 \mathrm{mM}$ dNTPs, $0.8 \mu \mathrm{l}$ of each primer $(5 \mu \mathrm{m}), 0.4 \mu \mathrm{l}$ of FastPfu Polymerase, and $1 \mu \mathrm{l}(10 \mathrm{ng} / \mu \mathrm{l})$ of template DNA. Resulting PCR products were extracted from a $2 \%$ agarose gel and further purified using the AxyPrep DNA Gel Extraction Kit (Axygen Biosciences, Union City, CA, United States) before being quantified using the QuantiFluor ${ }^{\mathrm{TM}}$-ST (Promega, United States) according to the manufacturer's protocol. Purified amplicons were pooled in equimolar amounts and paired-end sequenced $(2 \times 300 \mathrm{bp})$ on an Illumina MiSeq platform (Illumina, San Diego, United States) according to the manufacturer's protocols by Majorbio Bio-Pharm Technology Co. Ltd. (Shanghai, China).

\section{Processing of Sequencing Data}

All raw Illumina Fastq files were demultiplexed and qualityfiltered using Trimmomatic and merged using FLASH (Magoc and Salzberg, 2011). Operational taxonomic unit numbers (OTUs) were clustered with a $97 \%$ similarity cutoff using UPARSE (version 7.1), ${ }^{1}$ and chimeric sequences were identified and removed using UCHIME. The taxonomy of each 16S rRNA gene sequence was identified using the RDP Classifier algorithm ${ }^{2}$ against the Silva (SSU128) 16S rRNA database using a $70 \%$ confidence threshold.

\section{Bioinformatics and Statistical Analyses}

Rarefaction curves, composition, and alpha diversity analyses were performed on https://cloud.majorbio.com/.Principal coordinates analysis (PCoA) was performed on weighted UniFrac distance matrices (Lozupone and Knight, 2005) using the "amplicon" package (Liu et al., 2021) in R (v3.6.1). Permutational multivariate analysis of variance (PERMANOVA) was conducted using the adonis function of Vegan in R. Co-occurrence network analyses were carried out using the "igraph" package (Csardi and Nepusz, 2006) in R, and networks were visualized using Gephi (v0.9.2; Bastian et al., 2009). Linear discriminant analysis effect size (LEfSe) was applied to the OTU table using Galaxy. ${ }^{3}$ Venn diagrams and Phylogenetic Investigation of Communities by Reconstruction of Unobserved States (PICRUSt) were constructed via ImageGP. ${ }^{4}$

\footnotetext{
${ }^{1}$ http://drive5.com/uparse/

${ }^{2}$ http://rdp.cme.msu.edu/

${ }^{3}$ http://huttenhower.sph.harvard.edu/galaxy/

${ }^{4}$ http://www.ehbio.com/ImageGP/index.php/Home/Index/index.html
} 
SPSS v25.0 was used to perform paired sample $t$-tests, one-way ANOVA, and Spearman's rank correlations. A heat map of the relative abundance of bacterial taxa or pathways was constructed in TBTools v1.089 (Chen et al., 2020).

\section{Isolation and Molecular Identification of Bacterial Isolates of Rice Roots}

Endophytic bacteria of root were isolated as described by Zhou et al. (2020) with some modifications. $0.5 \mathrm{~g}$ of the surfacesterilized roots was triturated aseptically in distilled water and inoculated into $30 \mathrm{ml}$ of R2A (Massa et al., 1998), TSB (tryptone $1.5 \%$; soya peptone $0.5 \%$; $\mathrm{NaCl} 0.5 \%$; $\mathrm{pH} 7.4$ ), or $1 / 2 \mathrm{LB}$ broth (tryptone $0.5 \%$; yeast extract $0.25 \%$; $\mathrm{NaCl} 0.25 \%$; $\mathrm{pH} 7.4$ ), respectively. After incubation at $30^{\circ} \mathrm{C}$ for $24 \mathrm{~h}$, bacterial suspension was diluted appropriately. Aliquots of $100 \mu \mathrm{l}$ resuspension were spread on corresponding solid medium and incubated at $30^{\circ} \mathrm{C}$ until all colonies appeared. The colonies with distinctive morphological characteristics were picked and purified.

The isolates were identified by $16 \mathrm{~S}$ rDNA sequencing. The gene was amplified using universal primers $27 \mathrm{f}$ ( $5^{\prime}$-AGAGTTT GATCCTGGCTCA-3') and 1492r (5'-GGTTACCTTGTTACGA CTT-3'; Weisburg et al., 1991) and sequenced using an ABI 3730 Genetic Analyzer by RuiBiotech (Beijing). The sequences were used to perform BLASTN program against the $16 \mathrm{~S}$ database of type strains at EzTaxon server (Kim and Chun, 2014).

\section{Characterization of $\mathbf{C d}$ Tolerance and Plant Growth-Promoting Potential of Bacterial Isolates}

We used the broth microdilution method to test the minimum inhibitory concentration (MIC) of Cd upon bacterial strains (Wiegand et al., 2008). A 96-well microtiter plate was taken from its sterile packing, and $50 \mu$ of each $\mathrm{LB}+\mathrm{CdCl}_{2}$ dilution was added into the respective well (1st-10th), $100 \mu \mathrm{l}$ of LB broth in the control well (11th), and $50 \mu$ in the growth control well (12th). The bacterial suspension was adjusted to $1 \times 10^{8}$ colony-forming unit/ml (equal to McFarland 0.5 standard) and then diluted 100 times. Each well containing the $\mathrm{LB}+\mathrm{CdCl}_{2}$ solution (1st-10th) and the growth control well (12th) was inoculated with $50 \mu \mathrm{l}$ of the bacterial suspension, respectively. The final concentrations of $\mathrm{CdCl}_{2}$ in the 1 st-10th wells were $5,10,20,40,80,160,320,640,1,280$, and $2,560 \mu \mathrm{m}$, respectively. The microtiter plate was incubated at $37^{\circ} \mathrm{C}$ for $16-20 \mathrm{~h}$. The MIC is defined as the lowest concentration of the antimicrobial agent that inhibits visible growth of the tested isolate as observed with the unaided eye. Each sample was repeated three times.

The PGP traits of bacterial isolates were quantitatively analyzed as follows: Indole-3-acetic acid (IAA) production was estimated using Salkowski reagent (Glickmann and Dessaux, 1995); siderophore production was determined using the Chrome Azurol S agar method (Schwyn and Neilands, 1987); phosphate solubilization estimations were carried out via the molybdenum blue method (Murphy and Riley, 1962), and 1-aminocyclopropane-1-carboxylate
(ACC) deaminase activity was measured as described by Penrose and Glick (2003).

\section{RESULTS}

\section{Cd Accumulation in Roots of Five Cultivars at Two Stages}

ICP-MS was used to determine Cd content in root samples collected at the vegetative and reproductive stage (Figure 1A). At the vegetative stage, RBQ accumulates more Cd than other cultivars. This phenomenon is more pronounced at the reproductive stage, when RBQ has a significantly higher $\mathrm{Cd}$ content, followed by LA cultivars (728B and NX1B) and HA cultivars (BB and S95B). It appears that the LA cultivars accumulate more $\mathrm{Cd}$ in roots than those of HA cultivars.

\section{Diversity and Abundance of Endophytic Bacterial Communities}

A total of 1,236,157 16S rDNA sequences were obtained from root samples and were assigned to 2,261 OTUs based on $97 \%$ sequence similarity. Rarefaction curves of all samples tend to approach a saturation plateau, indicating that the sequencing accurately captures the endophytic communities of each rice cultivar (Supplementary Figure 1). The OTUs of rice cultivar $\mathrm{RBQ}, 728 \mathrm{~B}, \mathrm{NX} 1 \mathrm{~B}, \mathrm{BB}$, and $\mathrm{S} 95 \mathrm{~B}$ are $376,309,356,448$, and 359 , respectively, at the vegetative stage and $686,674,691$, 540 , and 514, respectively, at the reproductive stage.

According to the taxonomic affiliations of the OTUs, there are 37 phyla (97.30\% classified), 78 classes (92.30\% classified), 175 orders ( $91.43 \%$ classified), 329 families ( $89.36 \%$ classified), and 614 genera $(87.30 \%$ classified $)$ in rice root endophytic communities. Among all rice cultivars, the dominant phyla include Proteobacteria (81.08\%), Firmicutes (9.61\%), Actinobacteria (5.16\%), Acidobacteria (1.21\%), Bacteroidetes (0.70\%), and Spirochaetes $(0.68 \%)$. The dominant classes include Gammaproteobacteria (56.13\%), Betaproteobacteria (13.78\%), Clostridia (8.15\%), Alphaproteobacteria (7.76\%), Actinobacteria (5.16\%), Deltaproteobacteria (3.40\%), Bacilli (1.43\%), and Acidobacteria (1.21\%; Figure 1C). The dominant genera include Pseudomonas (55.12\%), Ralstonia (4.11\%), Burkholderia-Paraburkholderia (3.90\%), Bradyrhizobium (2.34\%), ClostridiumSensu_Stricto_1 (1.43\%), Sideroxydans (1.37\%), Kineosporia (1.43\%), Anaeromyxobacter (1.23\%), and Bacillus (1.10\%; Figure 1D).

\section{Shifts of Bacterial Community Structures During Two Developmental Stage of Rice}

PCoA was used to compare the bacterial community composition at the OTU level at two stages. PCoA1 and PCoA2 explain 43.87 and $8.81 \%$, respectively, of the observed variation (Figure 1B). The samples from the vegetative stage and reproductive stage separate clearly into two groups, indicating that the developmental stage governs a larger source of variation. PERMANOVA based on weighted UniFrac distances confirms that the developmental stage significantly influences the composition of bacterial communities $(14 \%, p<0.01)$. The rice 


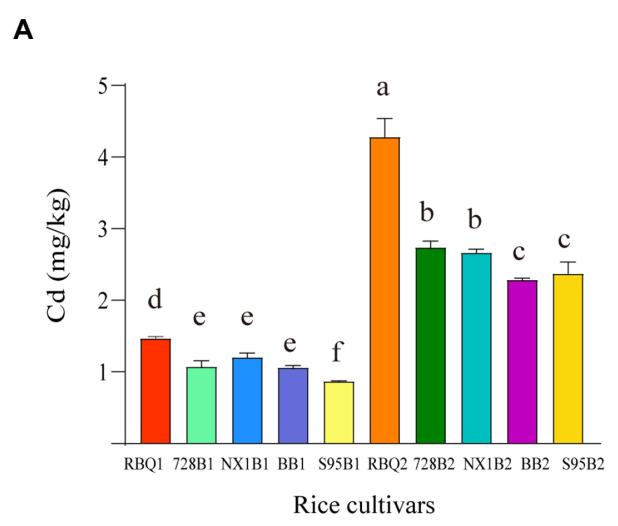

C

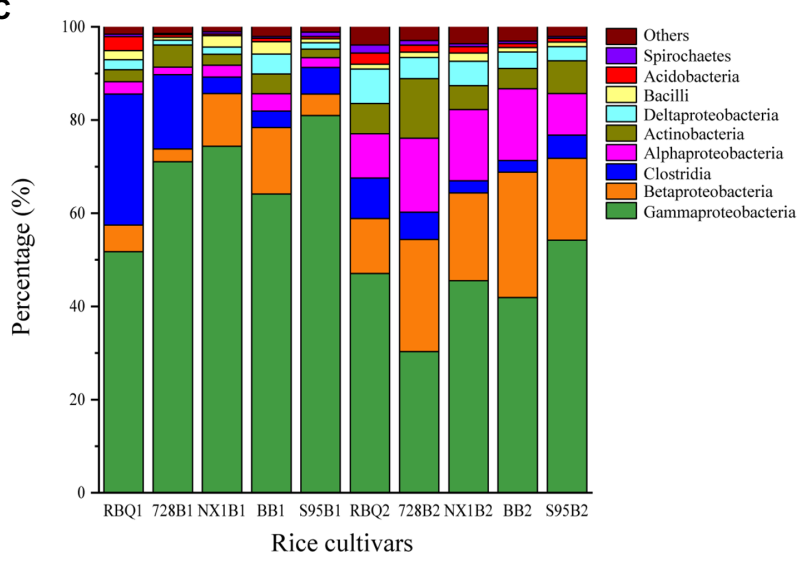

B

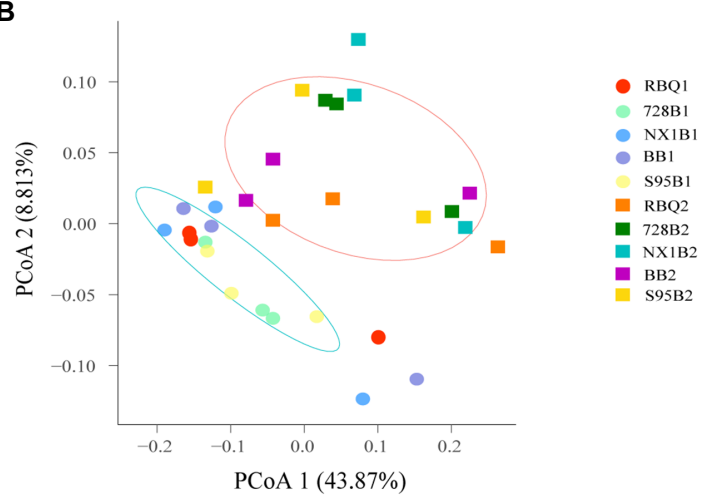

D

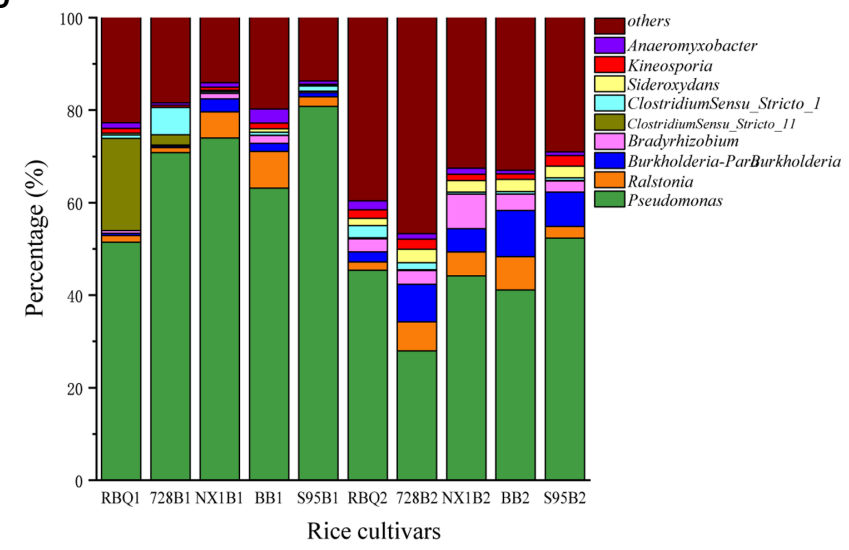

FIGURE 1 | Cd content in roots of five rice cultivars at the vegetative and reproductive stages (A); Principal coordinate analysis (PCoA) based on weighted UniFrac distance matrices at observed operational taxonomic unit (OTU) level (B); relative abundances of the dominant classes (C) and genera (D); hereafter, the cultivar name followed by 1 represents the vegetative stage and by 2 represents the reproductive stage. The different lowercase letters indicate significant differences among cultivars at $p<0.05$.

TABLE 1 | Permutational multivariate analysis of variance (PERMANOVA) results using weighted UniFrac distance matrices show effects of rice developmental stage, cultivar, and root Cd content on the bacterial community compositions.

\begin{tabular}{lrrrr}
\hline Factor & \% Explained & F. Model & $\boldsymbol{R}^{\mathbf{2}}$ & value of $\boldsymbol{p}$ \\
\hline Cultivar & 15.07 & 1.32 & 0.15 & 0.25 \\
Stage & 14.04 & 4.90 & 0.14 & $0.011^{*}$ \\
Cd & 2.35 & 0.82 & 0.02 & 0.493 \\
Cultivar: Stage & 7.72 & 0.67 & 0.08 & 0.771 \\
Cultivar: Cd & 12.15 & 1.06 & 0.12 & 0.432 \\
Stage: Cd & 5.52 & 1.93 & 0.06 & 0.144 \\
Cultivar: Stage: Cd & 14.52 & 1.27 & 0.15 & 0.259 \\
Residuals & 28.64 & & 0.29 & \\
Total & 100.00 & & 1.00 & \\
\hline
\end{tabular}

* denotes significant differences at $p<0.05$.

cultivars do not differ significantly in bacterial compositions $(p=0.25)$. The $\mathrm{Cd}$ content explains $2 \%$ of the observed variance, but not significantly different $(p=0.493$; Table 1).

In order to demonstrate the composition shifts of the endophytic bacterial communities at two developmental stages, two-sample $t$-tests were used to compare $\alpha$-diversity indices. The results shows that observed OTUs, Shannon index, ACE index, and Chaol at the reproductive stage are significantly higher than those at the vegetative stage $(p<0.01)$, while the Simpson index at the reproductive stage is significantly lower than that at the vegetative stage $(p<0.01)$, indicating that the endophytic bacterial community has much higher richness and diversity at the reproductive stage compared to the vegetative stage (Supplementary Table 1). ANOVA shows that $\alpha$-diversity indices among different cultivars are not statistically different (Figure 2, Supplementary Table 2).

The relative abundances of dominant endophytic bacterial taxa were further compared between two developmental stages. In comparison with the vegetative stage, the relative abundance of Alphaproteobacteria, Betaproteobacteria, Deltaproteobacteria, and Actinomycetes at the reproductive stage are significantly higher $(p<0.05)$, whereas the relative abundance of Gammaproteobacteria is significantly lower $(p<0.01)$. The relative abundance of Clostridia, Bacilli, and Acidobacteria does not show significant changes (Supplementary Table 3). At the genus level, the relative abundance of Burkholderia-Paraburkholderia, Bradyrhizobium, Sideroxydans, and Kineosporia is significantly higher $(p<0.01)$, whereas the abundance of Pseudomonas is significantly lower $(p<0.01)$. The relative abundance of Ralstonia, Clostridium_Sensu_Stricto_1, Clostridium_Sensu_Stricto_11, Anaeromyxobacter, and Bacillus does not show significant changes (Supplementary Table 4). 

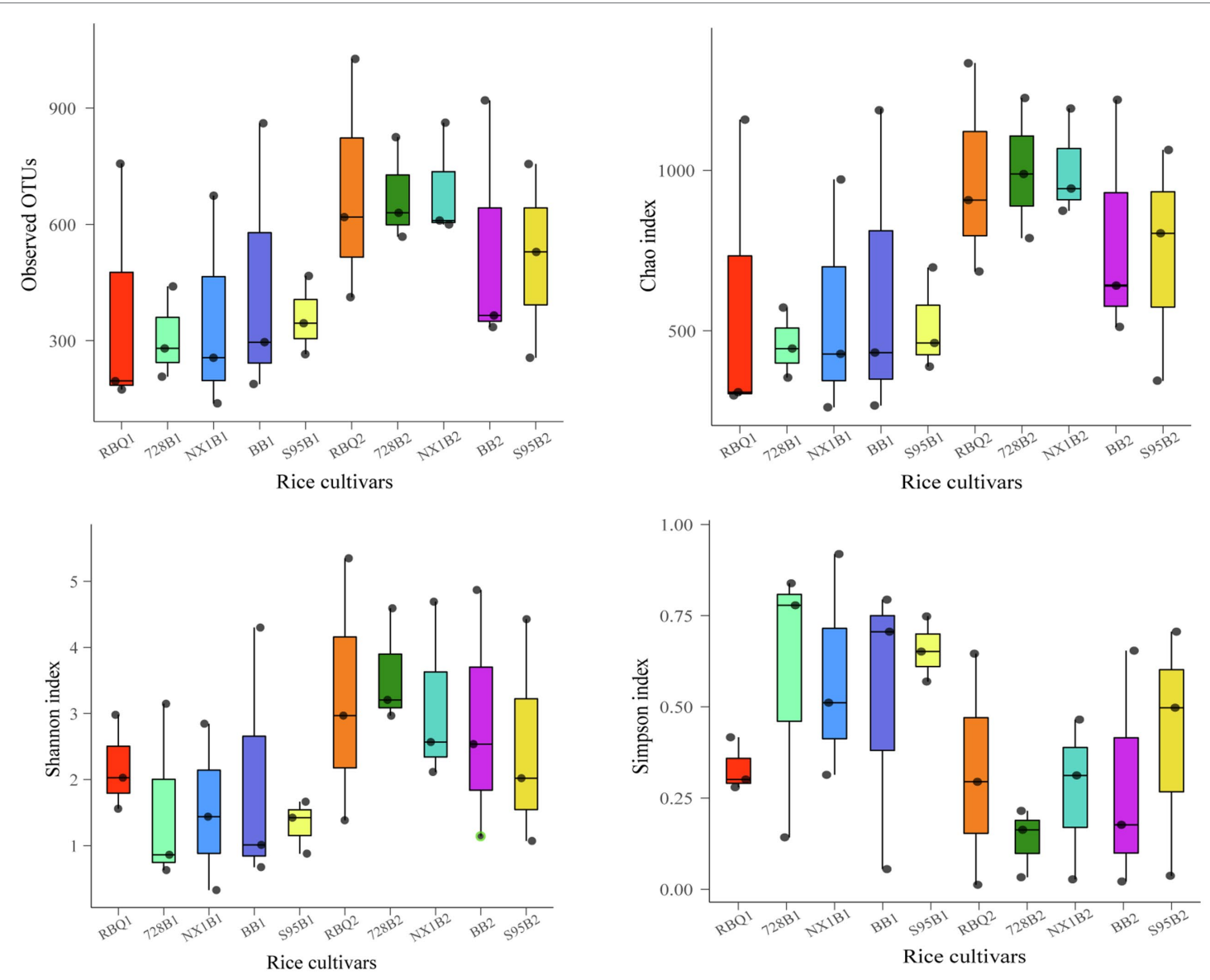

FIGURE 2 | Box plots of $\alpha$-diversity indices show observed OTUs, Shannon index, ACE index, and Chao1 of five rice cultivars at the vegetative and reproductive stages. The lines at the top, bottom, and middle of the box correspond to the 75th, 25th, and 50th percentiles (median), respectively. The ends of whiskers correspond to the minimum and maximum value.

\section{Co-occurrence Network Analysis of the Bacterial Community}

Co-occurrence bacterial network analysis shows different connectivity patterns at the two developmental stages. In general, the number of correlations is substantially larger at the reproductive stage than at the vegetative stage. At the vegetative stage, the network has 266 nodes with 4,277 edges, among which 4,215 are positively correlated and 62 are negatively correlated, and the average degree of the network is 32.16 . At the reproductive stage, the network has 425 nodes with 11,659 edges, among which 10,763 are positively correlated, and 896 are negatively correlated, and the average degree of the network is 54.87 (Figure 3, Supplementary Table 5). These findings indicate a higher complexity of the bacterial networks at the reproductive stage than at the vegetative stage.

The taxonomy of the most connected nodes varies between the vegetative and reproductive stages. At the vegetative stage, Actinobacteria accounts for $17.36 \%$ of the total degree of connection, followed by Betaproteobacteria (16.79\%), Deltaproteobacteria (14.37\%), Alphaproteobacteria (11.34\%), and Clostridia (9.84\%). At the reproductive stage, Betaproteobacteria accounts for $23.89 \%$ of the total degree of connection, followed by Deltaproteobacteria (22.35\%), Actinobacteria (9.16\%), Alphaproteobacteria (7.15\%), and Acidobacteria (6.38\%; Supplementary Table 6).

According to degree centrality, we classified the most central $20 \%$ as key nodes (Xian et al., 2020). The relative abundance of the key nodes at each developmental stage varies greatly, ranging from $0.005 \%$ to $1 \%$. Several of the highly connected taxa, such as Anaeromyxobacter, Geobacter, Haliangium, kineosporia, and Streptomyces at the vegetative stage and Ralstonia, Haliangium, Sideroxydans, Geobacter, Anaeromyxobacter, Bradyrhizobium and Micromonospora at the reproductive stage, appear to be the keystone bacterial taxa (Supplementary Figure 2).

\section{Cultivar-Associated Bacterial Biomarkers and Specific OTUs}

In order to detect the bacterial taxonomic biomarkers of each cultivar, OTUs with relative abundance greater than $0.05 \%$ were compared between samples using LEfSe [linear discriminant analysis (LDA) effect size]. OTUs with the highest LDA (Wilcoxon 


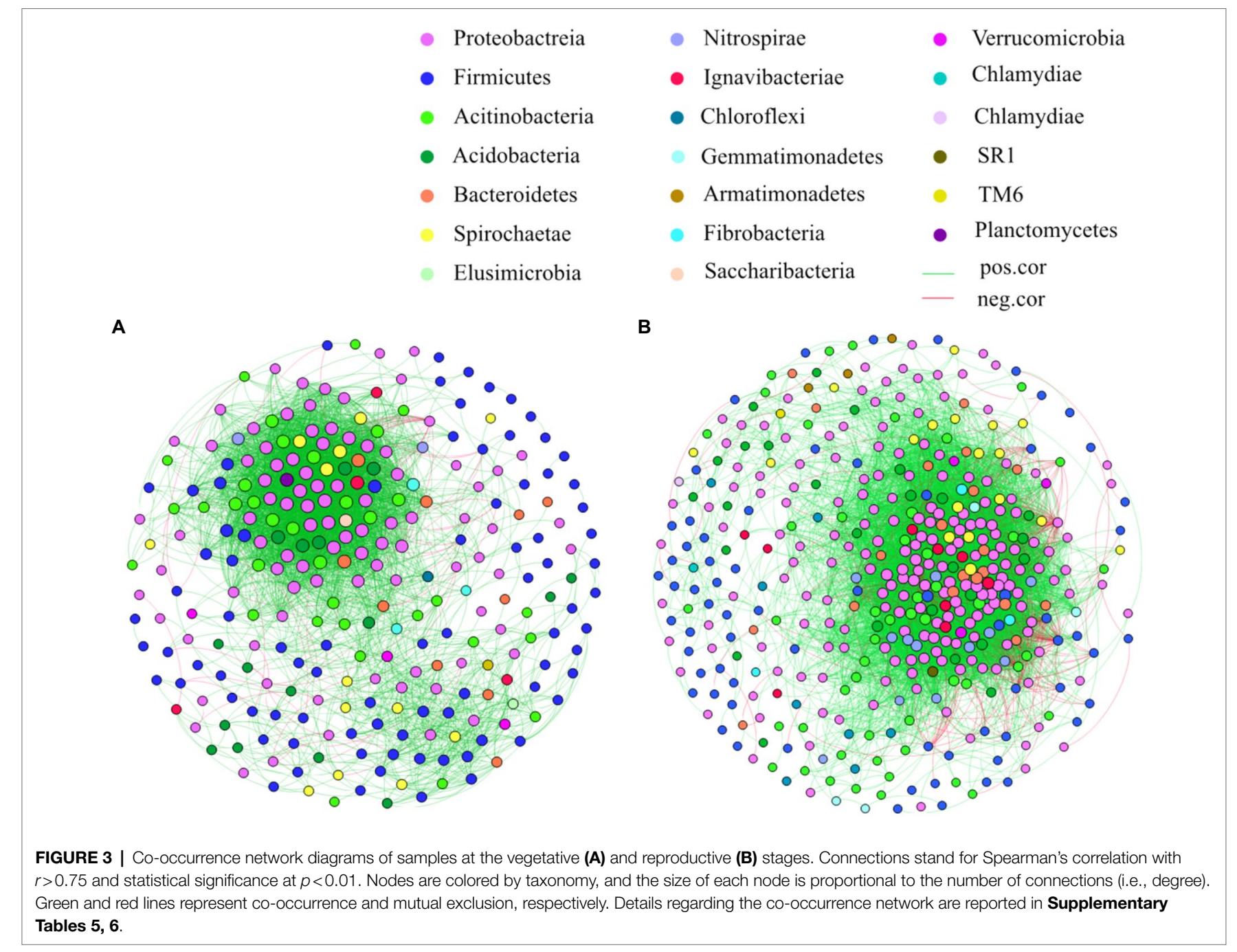

$p<0.05$, LDA score $>3$ ) from each cultivar are shown in Figure 4. At the vegetative stage, only cultivar $728 \mathrm{~B}$ and $\mathrm{BB}$ have differentially abundant clades, such as Micrococcaceae and Arthrobacter in BB. However, at the reproductive stage, all rice cultivars show differentially abundant clades, such as Ruminiclostridium_1 and Nocardia in RBQ; Methylcystiaceae and Hyphomicrobiaceae in 728B; Chloroflexi in NX1B; Sphingomonadaceae and Sphingomonas in BB; and Mycobacteriaceae and Mycobacterium in S95B (Figures 4A,B).

The Venn diagram shows a cluster of shared OTUs and the specific OTUs for each cultivar. At the vegetative stage, there are 12 shared OTUs (77.8\%) among different cultivars, mainly including Pseudomonas (OTU_538, 68.01\%), Ralstonia (OTU_1351,3.64\%), and Clostridium_Sensu_Stricto_1 (OTU_83, $1.53 \%)$. Specific OTUs of RBQ, 728B, NX1B, BB, and S95B at the vegetative stage account for $7.71,5.66,1.09,2.81$, and $1.19 \%$ of the bacterial communities, respectively (Figure 4C).

At the reproductive stage, there are 47 shared OTUs (77.60\%) among different cultivars, mainly including Pseudomonas (OTU_538, 42.17\%), Ralstonia (OTU_1351, 4.52\%), Burkholderia-Paraburkholderia (OTU_1265, 3.31\%; OTU_1568,
2.77\%), Sideroxydans (OTU_2233, 1.88\%), and Bradyrhizobium (OTU_1319, 1.88\%; OTU_389, 1.71\%). Specific OTUs of RBQ, $728 \mathrm{~B}, \mathrm{NX} 1 \mathrm{~B}, \mathrm{BB}$, and $\mathrm{S} 95 \mathrm{~B}$ at the reproductive stage account for $3.64,7.62,1.99,1.33$, and $1.05 \%$ of the bacterial communities, respectively (Figure $4 \mathrm{D}$ ).

\section{Bacterial Taxa Correlated With Cd Contamination}

Spearman correlation analysis shows that 45 genera $(7.3 \%$ of observed genera) are significantly correlated with $\mathrm{Cd}$ content (Spearman's $r>0.75, p<0.01$, Supplementary Table 7). Among them, forty-one genera are positively correlated with Cd content, such as Geobacter, Haliangium, Uliginosibacterium, Ideonella, Micromonospora, and Geothrix. Four genera are negatively correlated with Cd content, including Pseudomonas, Arthrobacter, Streptacidiphilus, and Prolixibacter. Linear regressions between the abundances of the representative bacterial genera and the $\mathrm{Cd}$ content confirm the abundance of unique bacteria taxa correlated with the content of $\mathrm{Cd}$ in roots (Figure 5). 
A

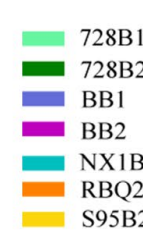

\section{Cladogram}

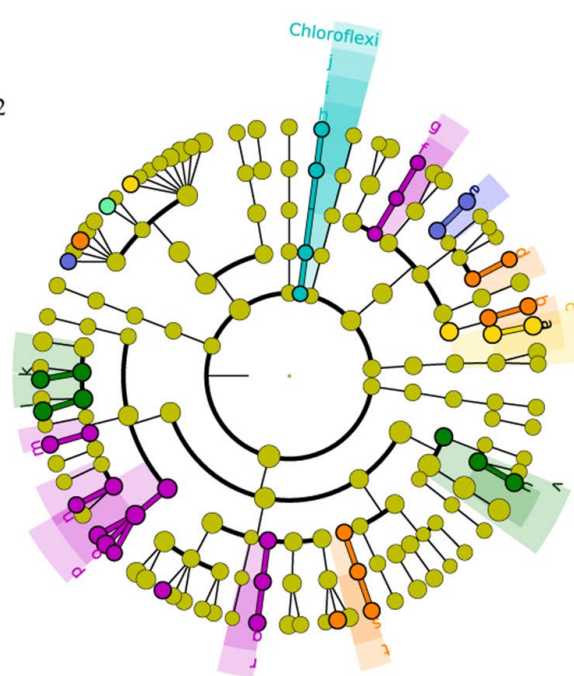

B

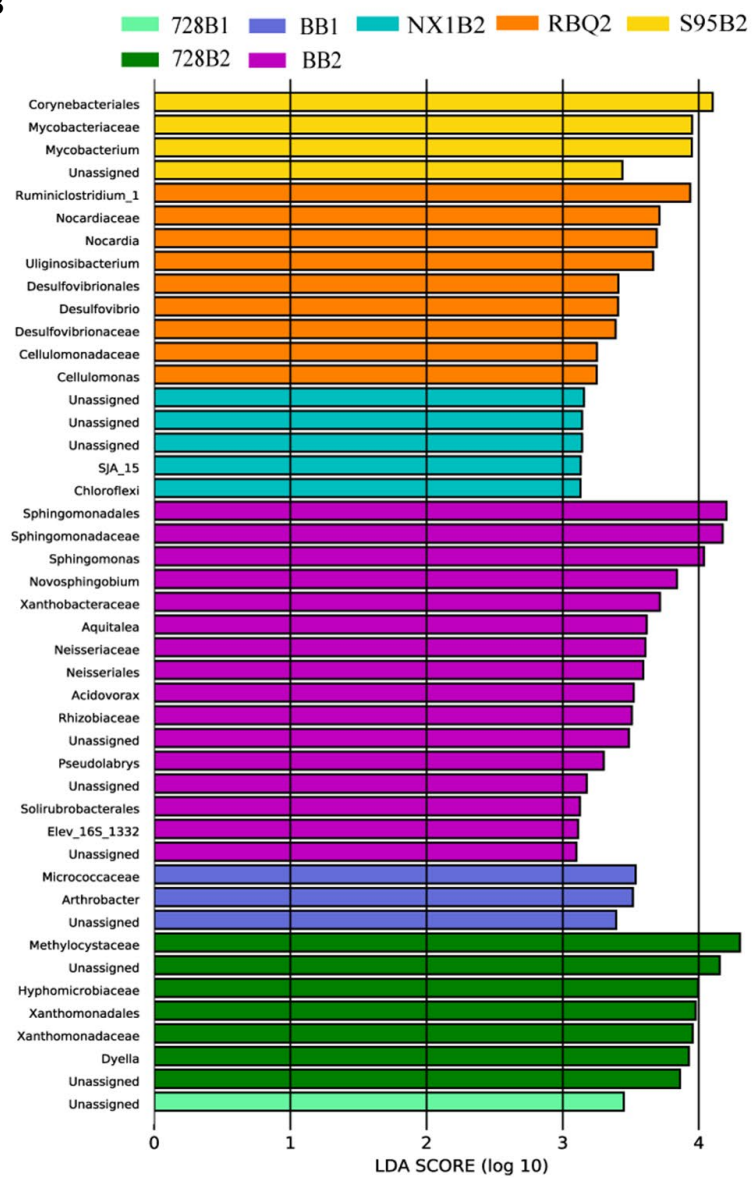

a: Mycobacteriaceae

b: Nocardiaceae

c: Corynebacteriales

d: Cellulomonadaceae

e: Micrococcaceae

f: Elev_16S_1332

g: Solirubrobacterales

h: Unassigned

i: Unassigned

j: SJA_15

k: Hyphomicrobiaceae

I: Methylocystaceae

m: Rhizobiaceae

n: Xanthobacteraceae

o: Xanthobacteraceae

p: Sphingomonadales

q: Neisseriaceae

r: Neisseriales

s: Desulfovibrionaceae

$\mathrm{t}$ : Desulfovibrionales

u: Xanthomonadaceae

v: Xanthomonadales

C

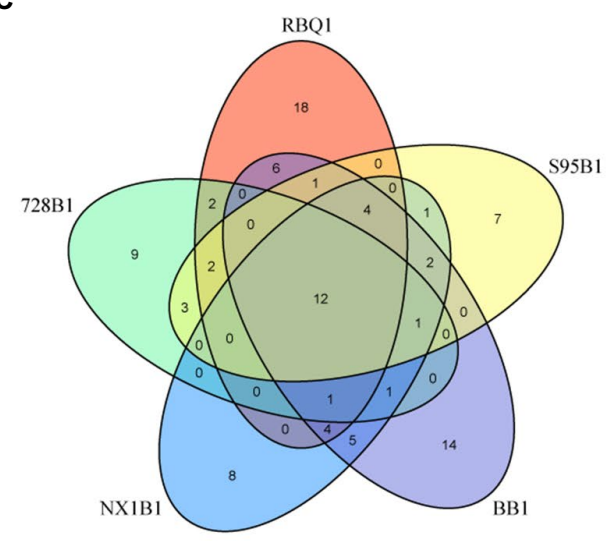

D

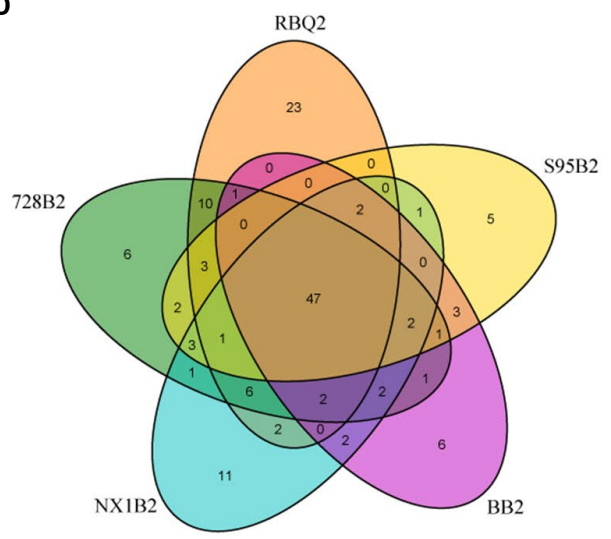

FIGURE 4 | (A-B)Taxonomic cladograms of linear discriminant analysis effect size (LEfSe) analysis of rice cultivars at two developmental stages, depicting OTUs with absolute linear discriminant analysis (LDA) scores larger than 3. Venn diagrams show shared and specific OTUs among five rice cultivars at the vegetative (C) and reproductive (D) stages. 


\section{Prediction of Functional Profiles of the Bacterial Community}

A total of 297 functional pathways were analyzed for endophytic bacterial communities. KEGG Orthology (KO)-based PcoA analysis reveals functional differences of five rice cultivars across two stages (Supplementary Figure 3). From the vegetative to the reproductive stage, a total of 42 metabolic pathways (representing $14 \%$ of predicted functions) are significantly changed $(p<0.05)$, including bacterial motility proteins, butanoate metabolism, propanoate metabolism, bacterial chemotaxis, lipid biosynthesis proteins, fatty acid metabolism, glyoxylate and dicarboxylate metabolism, cysteine and methionine metabolism, and the biosynthesis of type II polyketide products (Figure 6).

Grime's Competitor/Stress-tolerator/Ruderal (CSR) theory proposes that organisms in a community face a three-way resource trade-off: competition with neighbors for resources (Competitive traits); survival in underproductive environments (Stress-tolerant traits); and survival in highly disturbed environments (Ruderal traits; Grime, 1977; Grime and Pierce, 2012). According to CSR theory and the detailed criteria for functional traits described in Wood et al. (2018), six functional pathways are classified as $\mathrm{C}$ traits, 11 as $\mathrm{S}$ traits, and seven as $\mathrm{R}$ traits in this study (Supplementary Table 8). Comparison of CSR traits between the two developmental stages reveals that the relative abundances of $\mathrm{C}$ traits (biosynthesis of siderophore and type II polyketide products) and $\mathrm{S}$ traits (Porphyrin and chlorophyll metabolism and Proteasome) are significantly increased at the reproductive stage. Most metabolic pathways in the $\mathrm{R}$ traits are also enhanced, especially carbon fixation pathways, citrate cycle (TCA cycle), and oxidative phosphorylation.

\section{Cd Tolerance and PGP Potential of Cultivable Bacteria}

Forty-three strains isolated from $\mathrm{Cd}$-contaminated rice roots are ascribed to 12 genera in five classes (Supplementary Table 9). Among them, Bacillus comprises the largest number of taxa (53.5\%), followed by Klebsiella (11.6\%), Paenibacillus (7\%), and Herbaspirillum (7\%).

We tested the Cd tolerance and PGP traits of some representative isolates (Figure 7, Supplementary Table 10). The minimum inhibitory concentrations (MICs) of bacterial isolates to $\mathrm{Cd}$ are between 10 and 1,280 $\mu \mathrm{m}$, among which Bacillus sp. TB3 and

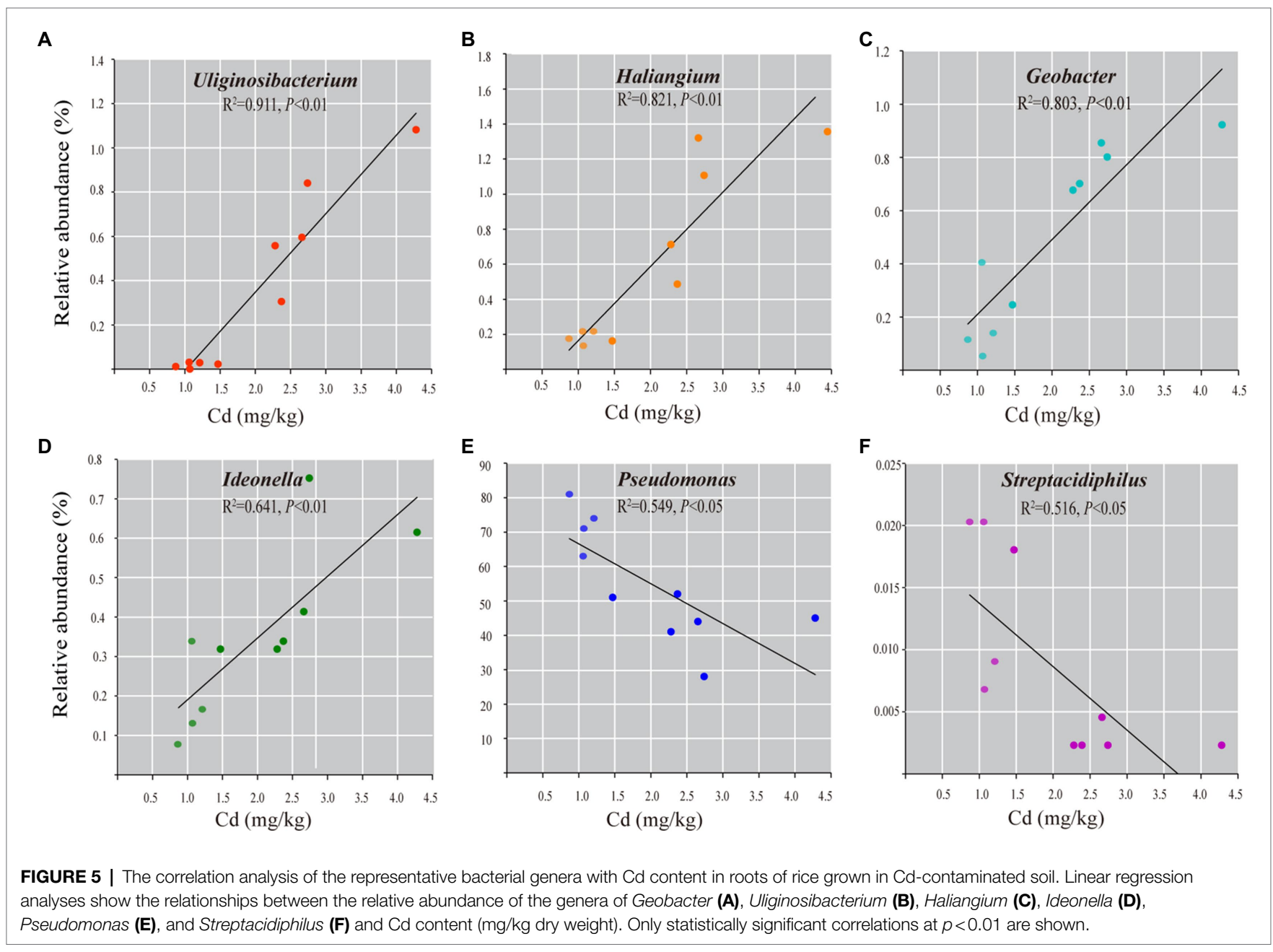




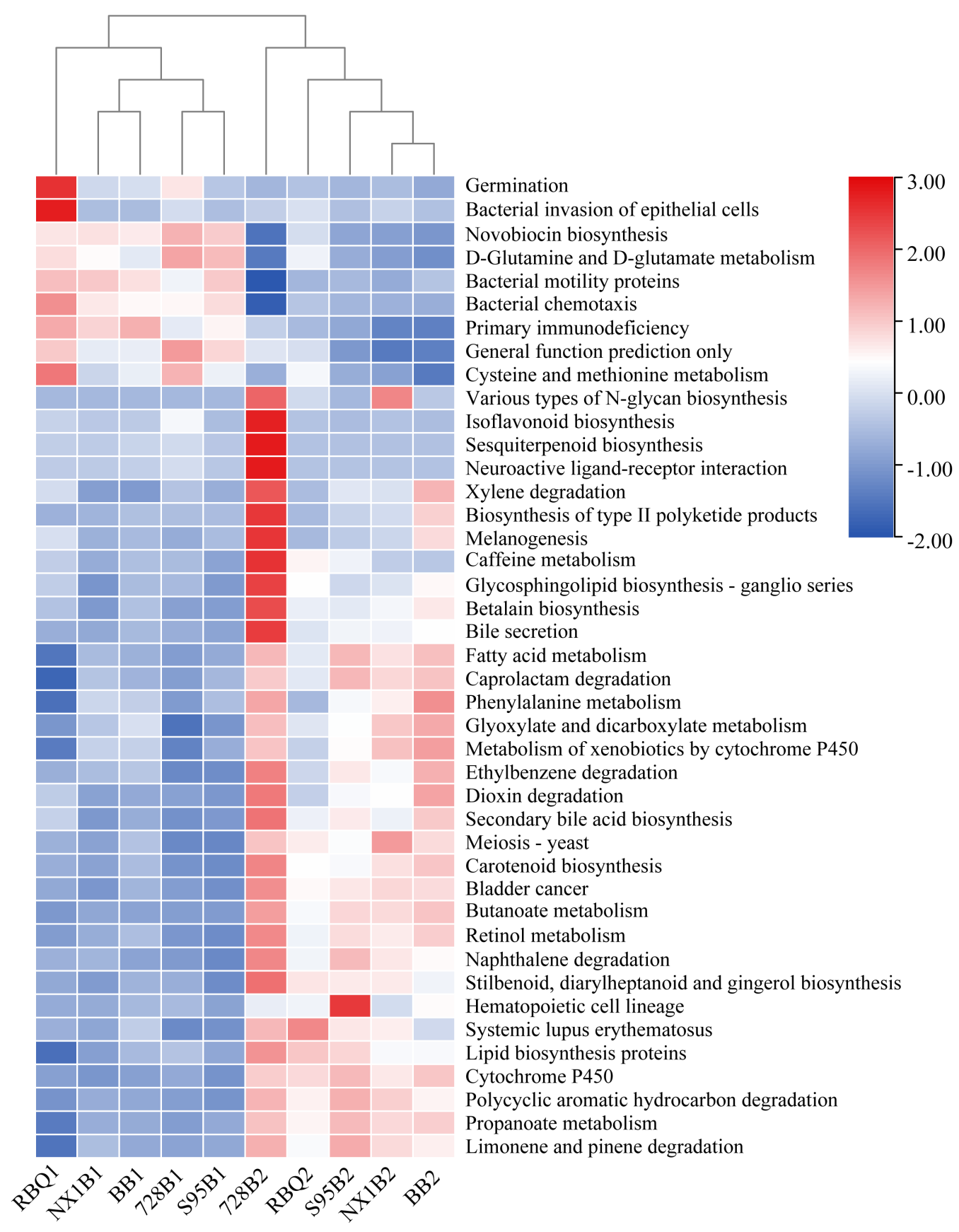

FIGURE 6 | Predicted gene functional categories of the endophytic microbiome of five rice cultivars at the vegetative and reproductive stages. The heat map is drawn for a total of 42 metabolic pathways which were significantly changed from the vegetative to reproductive stage.

TS1 show the highest tolerance $(1,280 \mu \mathrm{m})$. As for PGP traits, Klebsiella sp. RBB3 shows the highest IAA production $(52.84 \mu \mathrm{g} /$ $\mathrm{ml})$. Pseudomonas sp. 4-N2 shows the highest siderophore production (96.85 mg/l) and phosphate solubilization ability $(41.46 \mu \mathrm{g} / \mathrm{ml})$. The activity of ACC deaminase is highest for Bacillus sp. TB1 (12.84U/ $\mathrm{mg}$ ), whereas some isolates are negative for the assay. Most of the endophytic bacteria isolated from the Cd-contaminated roots show traits of a higher Cd resistance and PGP potential. The endophytic bacteria with those traits can be exploited as potential bioinoculants to enhance crop productivity and mitigate HM stress.

\section{DISCUSSION}

High-throughput sequencing studies have revealed a high diversity of endophytic bacteria in rice roots (Sun et al., 2008; 


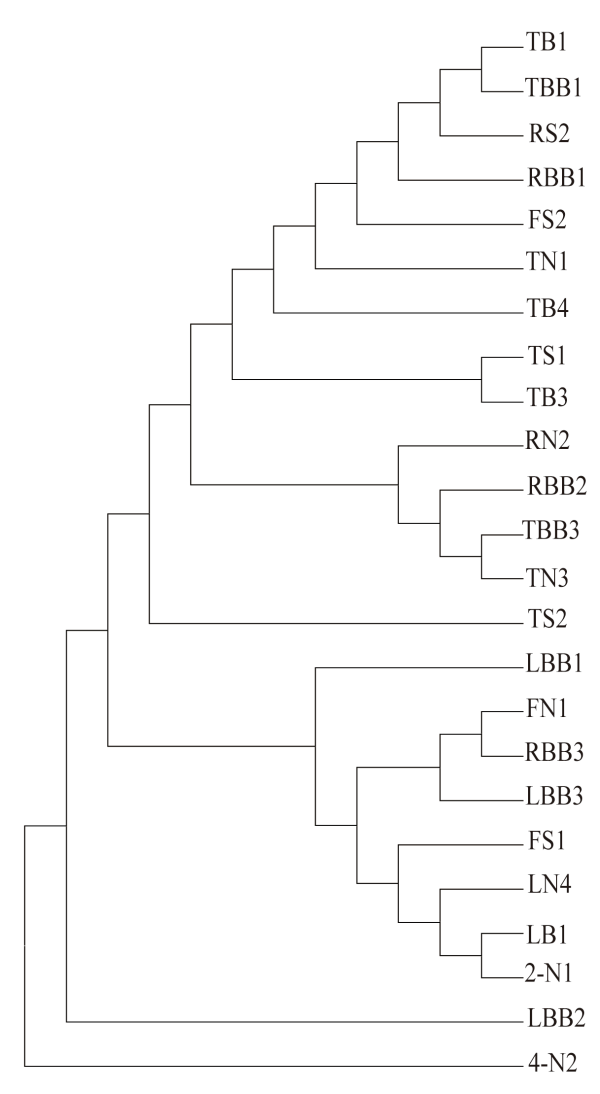

B. aryabhattai
B. aryabhattai
B. aryabhattai
B. zanthoxyli
B. aryabhattai
B. aryabhattai
B. koreensis
B. cereus
B. cereus
B. siamensis
B. siamensis
B. velezensi
B. velezensi
P. cucumis
B. vietnamiensis
C. bitternis
K. quasipneumoniae
P. dispersa
L. yeojuensis
A. ruhlandii
H. seropedicae
A. palustre
M. binotii
P. sesami

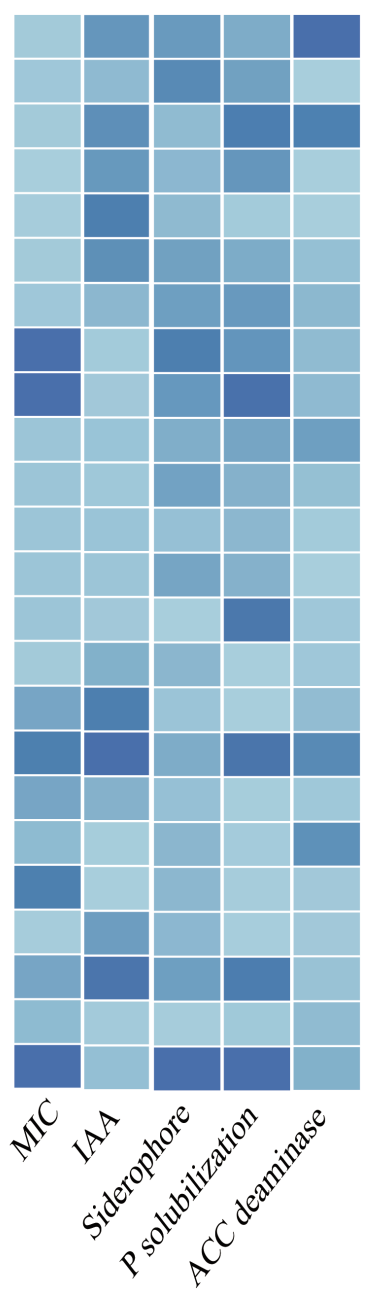

FIGURE 7 | Phylogenetic tree of the representative bacterial isolates and their minimum inhibitory concentrations (MICs) to Cd and plant growth-promoting (PGP) traits, including production of indole-3-acetic acid (IAA), siderophore, phosphate solubilization, and 1-aminocyclopropane-1-carboxylate (ACC) deaminase activities. The color gradient from dark to light represents the value from high to low.

Edwards et al., 2015; Ding et al., 2019; Walitang et al., 2019). In this study, by using five cultivars grown in a natural Cd-contaminated paddy field, we observed Proteobacteria, Firmicutes, Actinobacteria, Acidobacteria, Bacteroidetes, and Spirochaetes are the most dominant phyla, and Pseudomonas, Ralstonia, Burkholderia-Paraburkholderia, Bradyrhizobium, ClostridiumSensu_Stricto_1, Sideroxydans, Kineosporia, Anaeromyxobacter, and Bacillus are the most dominant genera.

The endophytic microbiota has been found to be beneficial to plant growth, nutrition uptake, and resistance to biotic and abiotic stresses (Castrillo et al., 2017; Kim and Lee, 2020). In this study, we found that Proteobacteria makes up the largest fraction of the bacterial communities, which include gamma, alpha, beta, and delta subclasses. In Alphaproteobacteria, Bradyrhizobium and Sphingomonas are two representatives reported to be nitrogen fixers (Knief et al., 2012; Sessitsch et al., 2012; Hardoim et al., 2015). In Betaproteobacteria,
Burkholderia-Paraburkholderia shows multiple phytobeneficial traits (Madhaiyan et al., 2008; King et al., 2019). Pseudomonas, affiliated to the Gammaproteobacteria, is the most abundant genus, which has been detected in various rice tissues, including root, stem, leaves, and seeds (Walitang et al., 2019). It has been reported that Pseudomonas can synthesize PGP substance (such as phytohormone) to facilitate plant growth or produce antibiotics to increase resistance to pathogens (Weller et al., 2002; Sivasakthi et al., 2013; Han et al., 2015). We found that Deltaproteobacteria is another dominant bacterial population in rice root. Compared with the root-associated bacteria of other crops, rice root is significantly enriched for Deltaproteobacteria (Ding et al., 2019). One possible explanation is that the flooded nature of rice cultivation could favor the growth of anaerobic microorganisms in the DeltaProteobacteria, such as Geobacter and Anaeromyxobacter, which are involved in the reduction of Fe (III) and S (Ding et al., 2015; Sun et al., 2015). 
Endophytic microbiota change with the growth and developmental stages of host plants (Santoyo et al., 2016). In this study, the alpha diversity indices (Observed OTUs, Shannon, ACE and Chao 1) of bacterial communities at the reproductive stage are significantly higher than that at the vegetative stage, indicating a more mature community is established at the reproductive stage. Other studies also reported that rice root microbiota varies dramatically during the vegetative stage and becomes stabilized during the reproductive stage until rice ripening (Edwards et al., 2018; Zhang et al., 2018). Xun et al. (2021) found that bacterial communities with a higher phylogenetic diversity are more stable and more resistant to environmental disturbance. Our co-occurrence network analysis further reveals that the endophytic bacterial community has established a complex symbiotic relationship during the reproductive stage. It is worth noting that although Pseudomonas and BurkholderiaParaburkholderia are the most dominant genera, they are not in the top $20 \%$ key nodes of the network. In contrast, Sideroxydans, Ralstonia, Haliangium, Bradyrhizobium, Micromonospora, Anaeromyxobacter, and Geobacter are the key nodes of the network. Among them, some species have been reported to participate in nitrogen fixation or $\mathrm{CO}_{2}$ fixation (Knief et al., 2012; Federico et al., 2015), phosphate solubilizing (Carro et al., 2018), and the iron cycle (Weiss et al., 2007; Ding et al., 2015). We suggest that the fundamental metabolic functions (especially nitrogen and carbon metabolism, phosphorus metabolism, and iron cycle) are the key engines for the assemblage of rice endophytic bacterial communities, which is in agreement with what has been found in soil microbiome (Xun et al., 2021).

Several studies have demonstrated that HM hyperaccumulating or tolerant plants harbor endophytic populations with a high HM resistance, indicating that an environmental stress influences the endophytic microbiomes (Luo et al., 2019; Zadel et al., 2020). As the Cd content in roots is significantly different among LA and HA cultivars, we further analyzed whether specific bacterial taxa may be affected by $\mathrm{Cd}$ contamination. Spearman correlation analysis shows that 45 genera are significantly correlated with $\mathrm{Cd}$ content. Some genera, which are positively correlated to $\mathrm{Cd}$ content, were also reported in other HM-polluted environments. For example, Geobacter and Geothrix are the two dominant genera in the uranium mine sediment (Li et al., 2018). Recent studies revealed that Geobacter, as a Fe (III)-reducing bacterium, plays an important role in controlling the mobility of As in the rice rhizosphere (Dai et al., 2020; Li et al., 2021). The negatively correlated genera, such as Pseudomonas and Arthrobacter, have been reported as the most represented genera in HM-contaminated sites (Pires et al., 2017). The inoculation of seeds with Pseudomonas or Arthrobacter has been shown to facilitate the root development of Brassica napus L. under the Zn/Cd stress (Croes et al., 2013; Montalban et al., 2016). In this study, Pseudomonas and Arthrobacter are enriched in roots with a low Cd content, suggesting their potential applications in alleviating HM stress in host plants.
In order to understand the characteristics of metabolic pathways of rice root endophyte under HM stress, PICRUSt and CSR theory (Grime, 1977; Grime and Pierce, 2012) were used to conduct a preliminary analysis of the functional characteristics of the endophytic bacterial communities. Wood et al. (2018) reveal that a bacterium's competitive attributes are critical for its ability to occupy and proliferate in a Cd-contaminated rhizosphere. In this study, we observe that the bacterial biosynthesis of type II polyketide products and siderophore ( $\mathrm{C}$ traits) is enriched at the reproductive stage, indicating that endophytic bacteria might promote host plant resistance to pathogens by synthesizing polyketide antibiotics and contribute to $\mathrm{Fe}$ uptake by siderophore production. Siderophores may also participate in chelating HM ions and thus reduce the toxicity of Cd to host plants (Etesami, 2018). Among $\mathrm{S}$ traits, porphyrin metabolism and proteasome function increase significantly. Mn-porphyrins are potent antioxidants, scavenging $\mathrm{O}^{2-}$ radicals (Miriyala et al., 2012), and proteasomes are involved in protein degradation and the recycling of amino acids (Becker and Darwin, 2017), suggesting that these two pathways may be involved in alleviating $\mathrm{HM}$-induced oxidative stress and removal of damaged proteins. As for $\mathrm{R}$ traits, the enhancement of carbon fixation pathways, citrate cycle (TCA cycle), and oxidative phosphorylation is favorable for endophytes to utilize nutrients for proliferation and occupying ecological niches.

From the above studies based on 16S rRNA gene amplicon sequencing and bioinformatic analysis, we profiled the root endophytic bacterial populations under $\mathrm{Cd}$ contamination. Based on these studies, we decided to isolate beneficial endophytic strains with potential applications in $\mathrm{HM}$ remediation. Plant growth-promoting bacteria (PGPB) are known to play a vital role in enhancing crop productivity and plant resistance to HM stresses (Etesami, 2018; Guo et al., 2020). Some genera affiliated to Bacillus, Neorhizobium, Delftia, Pseudomonas, Cupriavidus, and Stenotrophomonas have been reported to enhance rice growth and reduce the accumulation of HM in grains (Siripornadulsil and Siripornadulsil, 2013; Lin et al., 2016; Li et al., 2017; Liu et al., 2018; Treesubsuntorn et al., 2018). In this study, we isolated cadmium-resistant endophytic bacteria from 12 genera, including Bacillus, Paenibacillus, Klebsiella, Herbaspirillum, and Pseudomonas. Most of them show multiple PGP activities, such as phosphate solubilization, production of phytohormones (e.g., IAA), siderophores, and ACC deaminase. These activities suggest their beneficial roles in improving rice growth under stress conditions. Further studies are necessary to understand the highly complex interactions between rice and its associated microbe and to exploit the endophytic PGPB for remediation of HM contamination in paddy fields.

\section{DATA AVAILABILITY STATEMENT}

The datasets presented in this study can be found in online repositories. The names of the repository/repositories and 
accession number(s) can be found at: https://www.ncbi.nlm. nih.gov/, SRR11528738-SRR11528760 and MZ923694-MZ923717.

\section{AUTHOR CONTRIBUTIONS}

MF, NL, and CZ carried out the samples preparation and bacterial gDNA extraction. CC, MF, and CS performed bioinformatics and statistics analyses. CC and SF analyzed the Cd resistance and PGP traits of the isolates. CC and MF wrote the manuscript draft under the supervision of WW and ZY. All authors contributed to the article and approved the submitted version.

\section{FUNDING}

This research was financially supported by the Agricultural Science-Technology Innovation Fund of Hunan Province, China

\section{REFERENCES}

Afzal, I., Shinwari, Z. K., Sikandar, S., and Shahzad, S. (2019). Plant beneficial endophytic bacteria: mechanisms, diversity, host range and genetic determinants. Microbiol. Res. 221, 36-49. doi: 10.1016/j.micres.2019.02.001

Atafar, Z., Mesdaghinia, A., Nouri, J., Homaee, M., Yunesian, M., Ahmadimoghaddam, M., et al. (2010). Effect of fertilizer application on soil heavy metal concentration. Environ. Monit. Assess. 160, 83-89. doi: 10.1007/s10661-008-0659-x

Bastian, M., Heymann, S., and Jacomy, M. (2009). Gephi an open source software for exploring and manipulating networks. Third International AAAI Conference on Weblogs and Social Media 8, 361-362.

Becker, S. H., and Darwin, K. H. (2017). Bacterial proteasomes: mechanistic and functional insights. Microbiol. Mol. Biol. Rev. 81:e00036-16. doi: 10.1128/ mmbr.00036-16

Bulgarelli, D., Garrido-Oter, R., Münch, P. C., Weiman, A., Dröge, J., Pan, Y., et al. (2015). Structure and function of the bacterial root microbiota in wild and domesticated barley. Cell Host Microbe 17, 392-403. doi: 10.1016/j. chom.2015.01.011

Carro, L., Nouioui, I., Sangal, V., Meier-Kolthoff, J. P., Trujillo, M. E., Montero-Calasanz, M. D. C., et al. (2018). Genome-based classification of micromonosporae with a focus on their biotechnological and ecological potential. Sci. Rep. 8:525. doi: 10.1038/s41598-017-17392-0

Castrillo, G., Teixeira, P., Paredes, S. H., Law, T. F., Lorenzo, L. d., Feltcher, M. E., et al. (2017). Root microbiota drive direct integration of phosphate stress and immunity. Nature 543, 513-518. doi: 10.1038/nature21417

Chen, C., Chen, H., Zhang, Y., Thomas, H. R., Frank, M. H., He, Y., et al. (2020). TBtools: An integrative toolkit developed for interactive analyses of big biological data. Mol. Plant 13, 1194-1202. doi: 10.1016/j.molp.2020.06.009

Cheng, C., Nie, Z., He, L., and Sheng, X. (2020). Rice-derived facultative endophytic Serratia liquefaciens F2 decreases rice grain arsenic accumulation in arsenic-polluted soil. Environ. Pollut. 259:113832. doi: 10.1016/j. envpol.2019.113832

Croes, S., Weyens, N., Janssen, J., Vercampt, H., Colpaert, J. V., Carleer, R., et al. (2013). Bacterial communities associated with Brassica napus L. grown on trace element-contaminated and non-contaminated fields: a genotypic and phenotypic comparison. Microb. Biotechnol. 6, 371-384. doi: 10.1111/1751-7915.12057

Csardi, G., and Nepusz, T. (2006). The igraph software package for complex network research. Interjournal Complex Systems 1695, 1-9.

Dai, J., Tang, Z., Jiang, N., Kopittke, P. M., Zhao, F., and Wang, P. (2020). Increased arsenic mobilization in the rice rhizosphere is mediated by ironreducing bacteria. Environ. Pollut. 263:114561. doi: 10.1016/j.envpol. 2020.114561 (grant no. 2018QN03) and the Science and Technology Program of Changsha, China (grant no. kq1801033).

\section{ACKNOWLEDGMENTS}

We especially thank Drs. Larry Bowman, Zhihong Jane Yang, Phillip Patten for their assistance with English language and grammatical editing. We also thank Dr. Xiaohui Li for his helpful advice on statistical analysis.

\section{SUPPLEMENTARY MATERIAL}

The Supplementary Material for this article can be found online at: https://www.frontiersin.org/articles/10.3389/fmicb.2021.756327/ full\#supplementary-material

Ding, L., Cui, H., Nie, S., Long, X., Duan, G., and Zhu, Y. (2019). Microbiomes inhabiting rice roots and rhizosphere. FEMS Microbiol. Ecol. 95:fiz040. doi: 10.1093/femsec/fiz040

Ding, L., Su, J., Xu, H., Jia, Z., and Zhu, Y. (2015). Long-term nitrogen fertilization of paddy soil shifts iron-reducing microbial community revealed by RNA-(13)C-acetate probing coupled with pyrosequencing. ISME J. 9, 721-734. doi: 10.1038/ismej.2014.159

Edwards, J., Johnson, C., Santos-Medellin, C., Lurie, E., Podishetty, N. K., Bhatnagar, S., et al. (2015). Structure, variation, and assembly of the rootassociated microbiomes of rice. Proc. Natl. Acad. Sci. U. S. A. 112, E911E920. doi: 10.1073/pnas.1414592112

Edwards, J. A., Santos-Medellín, C. M., Liechty, Z. S., Nguyen, B., Lurie, E., Eason, S., et al. (2018). Compositional shifts in root-associated bacterial and archaeal microbiota track the plant life cycle in field-grown rice. PLoS Biol. 16:e2003862. doi: 10.1371/journal.pbio.2003862

Etesami, H. (2018). Bacterial mediated alleviation of heavy metal stress and decreased accumulation of metals in plant tissues: mechanisms and future prospects. Ecotoxicol. Environ. Saf. 147, 175-191. doi: 10.1016/j. ecoenv.2017.08.032

Federico, R., Eugenia, J. O., Ludo, D., and Roberto, D. P. (2015). Microbial fixation of $\mathrm{CO}_{2}$ in water bodies and in drylands to combat climate change, soil loss and desertification. New Biotechnol. 32, 109-120. doi: 10.1016/j. nbt.2013.12.002

Glickmann, E., and Dessaux, Y. (1995). A critical examination of the specificity of the salkowski reagent for indolic compounds produced by phytopathogenic bacteria. Appl. Environ. Microbiol. 61, 793-796. doi: 10.1128/ aem.61.2.793-796.1995

Grime, J. P. (1977). Evidence for the existence of three primary strategies in plants and its relevance to ecological and evolutionary theory. Am. Nat. 111, 1169-1194. doi: 10.1086/283244

Grime, J. P., and Pierce, S. (2012). The Evolutionary Strategies that Shape Ecosystems. Oxford: Wiley-Blackwell.

Guo, J., Muhammad, H., Lv, X., Wei, T., Ren, X., Jia, H., et al. (2020). Prospects and applications of plant growth promoting rhizobacteria to mitigate soil metal contamination: A review. Chemosphere 246:125823. doi: 10.1016/j. chemosphere.2020.125823

Han, Y., Wang, R., Yang, Z., Zhan, Y., Ma, Y., Ping, S., et al. (2015). 1-aminocyclopropane-1-carboxylate deaminase from pseudomonas stutzeri A1501 facilitates the growth of rice in the presence of salt or heavy metals. J. Microbiol. Biotechnol. 25, 1119-1128. doi: 10.4014/jmb.1412.12053

Hardoim, P. R., van Overbeek, L. S., Berg, G., Pirttilä, A. M., Compant, S., Campisano, A., et al. (2015). The hidden world within plants: ecological and evolutionary considerations for defining functioning of microbial endophytes. Microbiol. Mol. Biol. Rev. 79, 293-320. doi: 10.1128/ MMBR.00050-14 
Hou, D., Wang, R., Gao, X., Wang, K., Lin, Z., Ge, J., et al. (2018). Cultivarspecific response of bacterial community to cadmium contamination in the rhizosphere of rice (Oryza sativa L.). Environ. Pollut. 241, 63-73. doi: 10.1016/j.envpol.2018.04.121

Hu, Y., Cheng, H., and Tao, S. (2016). The challenges and solutions for cadmiumcontaminated rice in China: A critical review. Environ. Int. 92, 515-532. doi: 10.1016/j.envint.2016.04.042

$\mathrm{Hu}, \mathrm{M} ., \mathrm{Li}, \mathrm{F}$., Liu, C., and Wu, W. (2015). The diversity and abundance of As(III) oxidizers on root iron plaque is critical for arsenic bioavailability to rice. Sci. Rep. 5:13611. doi: 10.1038/srep13611

$\mathrm{Hu}, \mathrm{M}$., Sun, W., Krumins, V., and Li, F. (2019). Arsenic contamination influences microbial community structure and putative arsenic metabolism gene abundance in iron plaque on paddy rice root. Sci. Total Environ. 649, 405-412. doi: 10.1016/j.scitotenv.2018.08.388

Huang, S., and Jin, J. (2008). Status of heavy metals in agricultural soils as affected by different patterns of land use. Environ. Monit. Assess. 139, 317-327. doi: 10.1007/s10661-007-9838-4

Kim, M., and Chun, J. (2014). "16S rRNA gene-based identification of bacteria and archaea using the EzTaxon server," in New Approaches to Prokaryotic Systematics. Vol. 41. eds. M. Goodfellow, I. Sutcliffe and J. Chun (Elsevier), 61-74.

Kim, H., and Lee, Y. (2020). The rice microbiome: A model platform for crop holobiome. Phytobiomes J. 4, 5-18. doi: 10.1094/PBIOMES-07-19-0035-RVW

King, E., Wallner, A., Rimbault, I., Barrachina, C., Klonowska, A., Moulin, L., et al. (2019). Monitoring of rice transcriptional responses to contrasted colonizing patterns of phytobeneficial Burkholderia s.l. reveals a temporal shift in JA systemic response. Front. Plant Sci. 10:1141. doi: 10.3389/ fpls.2019.01141

Knief, C., Delmotte, N., Chaffron, S., Stark, M., Innerebner, G., Wassmann, R., et al. (2012). Metaproteogenomic analysis of microbial communities in the phyllosphere and rhizosphere of rice. ISME J. 6, 1378-1390. doi: 10.1038/ ismej.2011.192

Kossoff, D., Dubbin, W. E., Alfredsson, M., Edwards, S. J., Macklin, M. G., and Hudson-Edwards, K. A. (2014). Mine tailings dams: characteristics, failure, environmental impacts, and remediation. Appl. Geochem. 51, 229-245. doi: 10.1016/j.apgeochem.2014.09.010

Li, Y., Pang, H., He, L., Wang, Q., and Sheng, X. (2017). Cd immobilization and reduced tissue cd accumulation of rice (Oryza sativa wuyun-23) in the presence of heavy metal-resistant bacteria. Ecotoxicol. Environ. Saf. 138, 56-63. doi: 10.1016/j.ecoenv.2016.12.024

Li, B., Wu, W., Watson, D. B., Cardenas, E., Chao, Y., Phillips, D. H., et al. (2018). Bacterial community shift and coexisting/coexcluding patterns revealed by network analysis in a uranium-contaminated site after bioreduction followed by reoxidation. Appl. Environ. Microbiol. 84:e02885-17. doi: 10.1128/ aem.02885-17

Li, B., Xu, R., Sun, X., Han, F., Xiao, E., Chen, L., et al. (2021). Microbiomeenvironment interactions in antimony-contaminated rice paddies and the correlation of core microbiome with arsenic and antimony contamination. Chemosphere 263:128227. doi: 10.1016/j.chemosphere.2020.128227

Lin, X., Mou, R., Cao, Z., Xu, P., Wu, X., Zhu, Z., et al. (2016). Characterization of cadmium-resistant bacteria and their potential for reducing accumulation of cadmium in rice grains. Sci. Total Environ. 569, 97-104. doi: 10.1016/j. scitotenv.2016.06.121

Liu, Y., Qin, Y., Chen, T., Lu, M., Qian, X., Guo, X., et al. (2021). A practical guide to amplicon and metagenomic analysis of microbiome data. Protein Cell 12, 315-330. doi: 10.1007/s13238-020-00724-8

Liu, Y., Tie, B., Li, Y., Lei, M., Wei, X., Liu, X., et al. (2018). Inoculation of soil with cadmium-resistant bacterium Delftia sp. B9 reduces cadmium accumulation in rice (Oryza sativa L.) grains. Ecotoxicol. Environ. Saf. 163, 223-229. doi: 10.1016/j.ecoenv.2018.07.081

Lozupone, C., and Knight, R. (2005). UniFrac: a new phylogenetic method for comparing microbial communities. Appl. Environ. Microbiol. 71, 8228-8235. doi: 10.1128/AEM.71.12.8228-8235.2005

Luo, J., Tao, Q., Jupa, R., Liu, Y., Wu, K., Song, Y., et al. (2019). Role of vertical transmission of shoot endophytes in root-associated microbiome assembly and heavy metal hyperaccumulation in sedum alfredii. Environ. Sci. Technol. 53, 6954-6963. doi: 10.1021/acs.est.9b01093

Luo, J., Tao, Q., Wu, K., Li, J., Qian, J., Liang, Y., et al. (2017). Structural and functional variability in root-associated bacterial microbiomes of $\mathrm{cd} / \mathrm{Zn}$ hyperaccumulator sedum alfredii. Appl. Microbiol. Biotechnol. 101, 7961-7976. doi: $10.1007 / \mathrm{s} 00253-017-8469-0$

Ma, Y., Rajkumar, M., Zhang, C., and Freitas, H. (2016). Beneficial role of bacterial endophytes in heavy metal phytoremediation. J. Environ. Manag. 174, 14-25. doi: 10.1016/j.jenvman.2016.02.047

Madhaiyan, M., Poonguzhali, S., Kwon, S. W., Song, M. H., and Sa, T. (2008). Molecular characterization of Burkholderia strains isolated from rice cultivars (Oryza sativa L.) for species identification and phylogenetic grouping. J. Microbiol. Biotechnol. 18, 1005-1010.

Magoc, T., and Salzberg, S. L. (2011). FLASH: fast length adjustment of short reads to improve genome assemblies. Bioinformatics 27, 2957-2963. doi: 10.1093/bioinformatics/btr507

Massa, S., Caruso, M., Trovatelli, F., and Tosques, M. (1998). Comparison of plate count agar and R2A medium for enumeration of heterotrophic bacteria in natural mineral water. World J. Microb. Biot. 14, 727-730. doi: 10.1023/A:1008893627877

Miriyala, S., Spasojevic, I., Tovmasyan, A., Salvemini, D., Vujaskovic, Z., St Clair, D., et al. (2012). Manganese superoxide dismutase, MnSOD and its mimics. Biochim. Biophys. Acta 1822, 794-814. doi: 10.1016/j. bbadis.2011.12.002

Montalban, B., Croes, S., Weyens, N., Lobo, M. C., Perez-Sanz, A., and Vangronsveld, J. (2016). Characterization of bacterial communities associated with Brassica napus L. growing on a $\mathrm{Zn}$-contaminated soil and their effects on root growth. Int. J. Phytoremediation 18, 985-993. doi: $10.1080 / 15226514.2016 .1183566$

Moronta-Barrios, F., Gionechetti, F., Pallavicini, A., Marys, E., and Venturi, V. (2018). Bacterial microbiota of rice roots: 16S-based taxonomic profiling of endophytic and rhizospheric diversity, endophytes isolation and simplified endophytic community. Microorganisms 6:14. doi: 10.3390/ microorganisms6010014

Murphy, J., and Riley, J. P. (1962). A modified single solution method for the determination of phosphate in natural waters. Anal. Chim. Acta 27, 31-36. doi: 10.1016/S0003-2670(00)88444-5

Penrose, D. M., and Glick, B. R. (2003). Methods for isolating and characterizing ACC deaminase-containing plant growth-promoting rhizobacteria. Physiol. Plant. 118, 10-15. doi: 10.1034/j.1399-3054.2003.00086.x

Pereira, S. I. A., and Castro, P. M. L. (2014). Diversity and characterization of culturable bacterial endophytes from Zea mays and their potential as plant growth-promoting agents in metal-degraded soils. Environ. Sci. Pollut. Res. Int. 21, 14110-14123. doi: 10.1007/s11356-014-3309-6

Pires, C., Franco, A. R., Pereira, S. I. A., Henriques, I., Correia, A., Magan, N., et al. (2017). Metal(loid)-contaminated soils as a source of culturable heterotrophic aerobic bacteria for remediation applications. Geomicrobiol J. 34, 760-768. doi: 10.1080/01490451.2016.1261968

Rajkumar, M., Sandhya, S., Prasad, M. N. V., and Freitas, H. (2012). Perspectives of plant-associated microbes in heavy metal phytoremediation. Biotechnol. $A d v$. 30, 1562-1574. doi: 10.1016/j.biotechadv.2012.04.011

Santoyo, G., Moreno-Hagelsieb, G., del Carmen Orozco-Mosqueda, M., and Glick, B. R. (2016). Plant growth-promoting bacterial endophytes. Microbiol. Res. 183, 92-99. doi: 10.1016/j.micres.2015.11.008

Schwyn, B., and Neilands, J. B. (1987). Universal chemical assay for the detection and determination of siderophores. Anal. Biochem. 160, 47-56. doi: 10.1016/0003-2697(87)90612-9

Sessitsch, A., Hardoim, P., Döring, J., Weilharter, A., Krause, A., Woyke, T., et al. (2012). Functional characteristics of an endophyte community colonizing rice roots as revealed by metagenomic analysis. Mol. Plant-Microbe Interact. 25, 28-36. doi: 10.1094/MPMI-08-11-0204

Siripornadulsil, S., and Siripornadulsil, W. (2013). Cadmium-tolerant bacteria reduce the uptake of cadmium in rice: potential for microbial bioremediation. Ecotoxicol. Environ. Saf. 94, 94-103. doi: 10.1016/j. ecoenv.2013.05.002

Sivasakthi, S., Kanchana, D., Usharani, G., and Saranraj, P. (2013). Production of plant growth promoting substance by Pseudomonas fluorescens and Bacillus subtilis isolates. Int. J. Microbiol. Res. 4, 227-233. doi: 10.5829/idosi. ijmr.2013.4.3.75171

Sun, L., Qiu, F., Zhang, X., Dai, X., Dong, X., and Song, W. (2008). Endophytic bacterial diversity in rice (Oryza sativa L.) roots estimated by $16 \mathrm{~S}$ rDNA sequence analysis. Microb. Ecol. 55, 415-424. doi: 10.1007/s00248-0079287-1 
Sun, M., Xiao, T., Ning, Z., Xiao, E., and Sun, W. (2015). Microbial community analysis in rice paddy soils irrigated by acid mine drainage contaminated water. Appl. Microbiol. Biotechnol. 99, 2911-2922. doi: 10.1007/s00253-014-6194-5

Sun, W., Xiong, Z., Chu, L., Li, W., Soares, M. A., White, J. F., et al. (2019). Bacterial communities of three plant species from $\mathrm{Pb}-\mathrm{Zn}$ contaminated sites and plant-growth promotional benefits of endophytic microbacterium sp. (strain BXGe71). J. Hazard. Mater. 370, 225-231. doi: 10.1016/j.jhazmat. 2018.02.003

Syranidou, E., Thijs, S., Avramidou, M., Weyens, N., Venieri, D., Pintelon, I., et al. (2018). Responses of the endophytic bacterial communities of Juncus acutus to pollution with metals, emerging organic pollutants and to bioaugmentation with indigenous strains. Front. Plant Sci. 9:1526. doi: 10.3389/fpls.2018.01526

Treesubsuntorn, C., Dhurakit, P., Khaksar, G., and Thiravetyan, P. (2018). Effect of microorganisms on reducing cadmium uptake and toxicity in rice (Oryza sativa L.). Environ. Sci. Pollut. Res. Int. 25, 25690-25701. doi: 10.1007/ s11356-017-9058-6

Walitang, D., Samaddar, S., Choudhury, A., Chatterjee, P., Ahmed, S., and Sa, T. (2019). "Diversity and plant growth-promoting potential of bacterial endophytes in rice," in Plant Growth Promoting Rhizobacteria (PGPR): Prospects for Sustainable Agriculture. ed. R. Z. Sayyed (Singapore: Springer), $1-17$.

Wang, P., Chen, H., Kopittke, P., and Zhao, F. (2019). Cadmium contamination in agricultural soils of China and the impact on food safety. Environ. Pollut. 249, 1038-1048. doi: 10.1016/j.envpol.2019.03.063

Weisburg, W. G., Barns, S. M., Pelletier, D. A., and Lane, D. J. (1991). 16 S ribosomal DNA amplification for phylogenetic study. J. Bacteriol. 173, 697-703. doi: $10.1128 /$ jb.173.2.697-703.1991

Weiss, J. V., Rentz, J. A., Plaia, T., Neubauer, S. C., Merrill-Floyd, M., Lilburn, T., et al. (2007). Characterization of neutrophilic Fe(II)-oxidizing bacteria isolated from the rhizosphere of wetland plants and description of Ferritrophicum radicicola gen. Nov. sp. nov., and Sideroxydans paludicola sp. nov. Geomicrobiol J. 24, 559-570. doi: 10.1080/01490450701670152

Weller, D. M., Raaijmakers, J. M., Gardener, B. B. M., and Thomashow, L. S. (2002). Microbial populations responsible for specific soil suppressiveness to plant pathogens. Annu. Rev. Phytopathol. 40, 309-348. doi: 10.1146/ annurev.phyto.40.030402.110010

Wiegand, I., Hilpert, K., and Hancock, R. E. W. (2008). Agar and broth dilution methods to determine the minimal inhibitory concentration (MIC) of antimicrobial substances. Nat. Protoc. 3, 163-175. doi: 10.1038/nprot. 2007.521

Wood, J. L., Tang, C., and Franks, A. E. (2018). Competitive traits are more important than stress-tolerance traits in a cadmium-contaminated rhizosphere:
A role for trait theory in microbial ecology. Front. Microbiol. 9:121. doi: 10.3389/fmicb.2018.00121

Xian, W., Salam, N., Li, M., Zhou, E., Yin, Y., Liu, Z., et al. (2020). Networkdirected efficient isolation of previously uncultivated Chloroflexi and related bacteria in hot spring microbial mats. NPJ Biofilms Microbiomes 6:20. doi: 10.1038/s41522-020-0131-4

Xun, W., Liu, Y., Li, W., Ren, Y., Xiong, W., Xu, Z., et al. (2021). Specialized metabolic functions of keystone taxa sustain soil microbiome stability. Microbiome 9:35. doi: 10.1186/s40168-020-00985-9

Yin, K., Wang, Q., Lv, M., and Chen, L. (2019). Microorganism remediation strategies towards heavy metals. Chem. Eng. J. 360, 1553-1563. doi: 10.1016/j. cej.2018.10.226

Zadel, U., Nesme, J., Michalke, B., Vestergaard, G., Płaza, G. A., Schröder, P., et al. (2020). Changes induced by heavy metals in the plant-associated microbiome of Miscanthus x giganteus. Sci. Total Environ. 711:134433. doi 10.1016/j.scitotenv.2019.134433

Zhang, J., Zhang, N., Liu, Y., Zhang, X., Hu, B., Qin, Y., et al. (2018). Root microbiota shift in rice correlates with resident time in the field and developmental stage. Sci. China Life Sci. 61, 613-621. doi: 10.1007/ s11427-018-9284-4

Zhou, J., Li, P., Meng, D., Gu, Y., Zheng, Z., Yin, H., et al. (2020). Isolation, characterization and inoculation of cd tolerant rice endophytes and their impacts on rice under cd contaminated environment. Environ. Pollut. 260:113990. doi: 10.1016/j.envpol.2020.113990

Conflict of Interest: The authors declare that the research was conducted in the absence of any commercial or financial relationships that could be construed as a potential conflict of interest.

Publisher's Note: All claims expressed in this article are solely those of the authors and do not necessarily represent those of their affiliated organizations, or those of the publisher, the editors and the reviewers. Any product that may be evaluated in this article, or claim that may be made by its manufacturer, is not guaranteed or endorsed by the publisher.

Copyright (C) 2021 Chu, Fan, Song, Li, Zhang, Fu, Wang and Yang. This is an open-access article distributed under the terms of the Creative Commons Attribution License (CC BY). The use, distribution or reproduction in other forums is permitted, provided the original author(s) and the copyright owner(s) are credited and that the original publication in this journal is cited, in accordance with accepted academic practice. No use, distribution or reproduction is permitted which does not comply with these terms. 